\title{
ANTENATAL ULTRASOUND DIAGNOSIS OF CONGENITAL ANOMALIES: A CENTRAL INDIAN PERSPECTIVE
}

\author{
Bhakti Gurjar1, Kshama Kedar², Anagha Deshpande ${ }^{3}$
}

${ }^{1}$ Assistant Professor, Department of Obstetrics and Gynaecology, Indira Gandhi Government Medical College, Nagpur. ${ }^{2}$ Associate Professor, Department of Obstetrics and Gynaecology, Indira Gandhi Government Medical College, Nagpur. ${ }_{3}^{3}$ Associate Professor, Department of Radiology, Indira Gandhi Government Medical College, Nagpur.

\begin{tabular}{l}
\hline ABSTRACT \\
BACKGROUND \\
Congenital anomalies are a global problem, but data on congenital anomalies from developing countries like India are limited. \\
We have tried to study antenatal ultrasound detection of anomalous pregnancies, as it can have an effect not only on patient \\
counselling but also on patient's decision for or against continuation of pregnancy, if it is diagnosed prior to 20 completed weeks and \\
subsequent management options.
\end{tabular}

\section{AIMS AND OBJECTIVES}

1. To study various congenital anomalies in singleton pregnancies detected antenatally by ultrasound examination.

2. To study the incidence of stillbirth in those diagnosed to have congenital anomalies on ultrasound examination.

\section{METHODS}

This was a hospital-based cross-sectional study conducted at a tertiary care hospital over a period of six months from January 2015 to June 2015. All women attending Antenatal Clinic were screened by ultrasound examination. Anomalies included in the study were classified by the organ system affected. All women who were diagnosed with major anomaly before 20 weeks of gestation were given a choice of medical termination of pregnancy. Women diagnosed later were observed closely throughout pregnancy and delivery.

\section{OBSERVATIONS AND RESULTS}

Out of a total of 2535 singleton pregnancies screened, 67 women were sonologically diagnosed to have congenital anomalies. The mean maternal age was 24.7 years. Mean gestational age at the time of diagnosis was 28.5 weeks. Majority women had an abnormal amount of Amniotic Fluid Index (AFI). The mean AFI was $13.7 \mathrm{~cm}$. Central Nervous System affection was the commonest followed by Renal and Cardiovascular System affection. All 9 women who were diagnosed prior to 20 weeks of gestation opted for medical termination of pregnancy. According to our study, the odds that a foetus having a congenital anomaly on Ultrasound examination will die in utero are 4.16 (1.72-10.01). Hence, the association between Congenital Anomaly and Stillbirth was found to be highly significant $(\mathrm{p}<0.01, \mathrm{HS})$. Clinical autopsy or genetic analysis was done for none of the babies.

\section{CONCLUSION}

Obstetric care providers should be conscious about counselling the patients diagnosed to be carrying anomalous child on Ultrasound regarding subsequent prognosis including high risk of stillbirth.

\section{KEYWORDS}

Congenital Anomalies, Ultrasound.

HOW TO CITE THIS ARTICLE: Gurjar B, Kedar K, Deshpande A. Antenatal ultrasound diagnosis of congenital anomalies: a central Indian perspective. J. Evolution Med. Dent. Sci. 2016;5(23):1251-1254, DOI: 10.14260/jemds/2016/291

\section{INTRODUCTION}

Congenital anomalies are a major universal problem, as every year an estimated 7.9 million children are born with a serious birth defect, 3.3 million children under five years of age die from birth defects and 3.2 million who survive may be disabled for life. ${ }^{1}$ Although, the reported incidence at birth is $2-3 \%$, actual occurrence is higher owing to a high number of first trimester abortions that remain undiagnosed. Data on congenital anomalies from developing countries like India are limited.

Financial or Other, Competing Interest: None.

Submission 29-01-2016, Peer Review 02-03-2016,

Acceptance 07-03-2016, Published 19-03-2016.

Corresponding Author:

Dr. Bhakti Gurjar,

Department of Obstetrics and Gynaecology,

Indira Gandhi Government Medical College,

Nagpur.

E-mail:drbhaktigurjar@ymail.com

DOI: $10.14260 /$ jemds/2016/291
It is important to have comprehensive and reliable data on description and prevalence of various congenital anomalies for surveillance, implementation of preventive public healthcare strategies as well as for management. The health care services from antenatal through obstetric to postnatal and adolescent healthcare are challenged with fundamental gaps in the understanding, prevention and treatment of congenital anomalies. In this study we have tried to study antenatal ultrasound detection of anomalous pregnancies, as it can have an effect not only on patient counselling but also on patient's decision for or against continuation of pregnancy, if it is diagnosed prior to 20 completed weeks and subsequent management options.

According to the World Health Organization (WHO) document of 1972, the term congenital malformations should be confined to structural defects at birth. ${ }^{2}$ However, as per the more recent WHO fact-sheet of October 2012, congenital anomalies can be defined as structural or functional anomalies 
including metabolic disorders, which are present at the time of birth. ${ }^{3}$ Congenital anomalies are an important cause of neonatal mortality both in developed and developing countries.

It accounts for $8-15 \%$ of perinatal deaths and $13-16 \%$ of neonatal deaths in India. 4,5 It is not only a leading cause of foetal loss, but also contributes significantly to preterm birth, childhood and adult morbidity along with considerable repercussion on the mothers and their families. Congenital anomalies contribute to a significant proportion of stillbirths worldwide and are one of the most commonly identifiable causes of stillbirth in the evaluation that ensues. ${ }^{6}$ with the advent and routine use of ultrasound, diagnosis of the anomaly is usually done antenatally. Unlike other risk factors, guidelines for the antenatal management of pregnancies complicated by isolated foetal anomalies are limited. ${ }^{7}$ In addition to the risk of stillbirth, foetuses with congenital anomalies are at risk of growth restriction. ${ }^{8}$ In this study, we also sought to estimate the incidence of stillbirth in foetuses with isolated congenital anomalies diagnosed during routine prenatal ultrasound evaluation.

\section{AIMS AND OBJECTIVES}

1. To study various congenital anomalies in singleton pregnancies detected antenatally by routine ultrasound examination.

2. To study the incidence of stillbirth in those diagnosed to have congenital anomalies on ultrasound examination.

\section{METHODS}

This was a hospital-based cross-sectional study conducted at a tertiary care hospital over a period of six months from $1^{\text {st }}$ January 2015 to $30^{\text {th }}$ June 2015 . The study was conducted using institutional database that includes demographic information, maternal history, pregnancy and neonatal outcomes. All women attending the Antenatal Clinic were screened by ultrasound examination (Level 1 scan) by qualified radiologist for foetal well-being at around 18 weeks of gestation. Women with multiple gestation were excluded from the study. Women who were diagnosed to be carrying anomalous foetuses were referred for a detailed anomaly scan by senior radiologist (Level 2 scan). Anomalies included in the study were classified by the organ system affected. All women who were diagnosed with major anomaly before 20 weeks of gestation were given a choice of medical termination of pregnancy. Women diagnosed later were observed closely throughout pregnancy and delivery. Stillbirth was defined as birth of a foetus not showing any signs of life at birth any time after 20 completed weeks of gestation.

Congenital anomalies were defined as any structural defect present at birth. Chromosomal analysis was not done and diagnoses were based on ultrasound and clinical findings. The paediatricians carried out an external examination for overt anomalies. Anomalies detected by the ultrasound followed a thorough physical examination at birth, supported when necessary by referral to specialists. Special investigations such as an echocardiogram were only done if there was clinical indication. Infants who had congenital anomalies involving more than one system were recorded once as having a multiple congenital anomaly. When no definite diagnosis was made, the infant was classified and coded as having an unspecified congenital anomaly.
The anomalies were classified by organ system according to the 10th version of the World Health Organization International Classification of Diseases (ICD-10; International Classification of Diseases, 2007). To find out the association between Ultrasound diagnosis of Congenital Anomaly and Stillbirth, we applied Chi-square test with the $95 \%$ confidence interval.

\section{OBSERVATIONS AND RESULTS}

Out of a total of 2535 singleton pregnancies screened, 67 women were sonologically diagnosed to have congenital anomalies. Majority, i.e. 37 out of 67 patients were multigravidae. Majority of women belonged to young age group between 20 to 24 years and the mean maternal age was 24.7 years. The age wise distribution of the women in study group is depicted in Table 1. Mean gestational age at the time of diagnosis was 28.5 weeks. Table 2 shows distribution of patients according to gestational age at the time of diagnosis. Majority of women had an abnormal amount of Amniotic Fluid Index (AFI), either too less or too high depending upon the type of congenital anomaly detected. The mean AFI was found to be $13.7 \mathrm{~cm}$.

Percentage wise distribution of various congenital anomalies as per systemic involvement detected by ultrasound is shown in Table 3. The commonest anomalies detected were Central Nervous System (CNS) anomalies. Out of a total 23 foetuses with CNS anomalies 16 had hydrocephalus, 4 had encephalocele, 2 had anencephaly and 1 had semilobar holoprosencephaly. Three foetuses with hydrocephalus were suspected to have aqueductal stenosis. One foetus with encephalocele also had Polycystic kidneys, Polydactyly, Hypotelorism and narrow thorax as a part of Meckel-Gruber Syndrome. Renal System affection was the second most common. Out of a total 16 foetuses with renal affection 11 had Hydronephrosis, 4 had Polycystic kidneys and 1 had a pelvic kidney. Of the foetuses with Hydronephrosis, 3 had Posterior urethral valve, one as a part of Megacystis Microcolon Hypoperistalsis Syndrome. One elderly primigravida had thickened nuchal pad, nasal bone hypoplasia, prominent cisterna magna and tricuspid regurgitation jet at 17 weeks of gestation. She opted for termination of pregnancy in view of high risk of Trisomy. One foetus with Achondrogenesis and Thanatophoric dysplasia was suspected to have Osteogenesis Imperfecta IIA.

All 9 women who were diagnosed early, i.e. prior to 20 weeks of gestation opted for medical termination of pregnancy. Rest of the women were followed closely and neonates were examined at birth for presence of anomalies. Clinical examination was consistent with Ultrasound findings in all the cases. There were 6 Stillbirths and 11 Early Neonatal deaths. Table 4 summarizes the association of presence of congenital anomaly on ultrasound examination with occurrence of stillbirth. According to our study, the odds that a foetus having a congenital anomaly on Ultrasound examination will die in utero are 4.16 (1.72-10.01). In contrast, out of 2468 foetuses that were found to be sonologically normal, only 57 died in utero. Hence, the association between congenital anomaly and stillbirth was found to be highly significant $(\mathrm{p}<0.01, \mathrm{HS})$. Clinical autopsy or genetic analysis was done for none of the babies because of unavailability of these tests at this Institute. 


\section{DISCUSSION}

With improved control of infections and nutritional deficiency diseases, congenital malformations have become important causes of perinatal mortality in developing countries like India. ${ }^{9}$ The pattern and prevalence of congenital anomalies may vary over time or with geographical location reflecting a complex interaction of known and unknown genetic and environmental factors including socio-cultural, racial and ethnic variables. ${ }^{10}$ Our study did not find any significant association of congenital anomalies with age or parity of the mother, probably because of a smaller sample size.

Central Nervous System anomalies were the commonest anomalies in our study, which is in accordance with some studies.11,12 while some studies had different results. Hydrocephalus was the commonest CNS anomaly in our study group. Even when ventriculomegaly was mild and appeared isolated, counseling of mothers was difficult because of uncertainty about the prognosis. Six foetuses had open neural tube defect, prevalence being 2.4 per 1000 births. This is comparatively higher than the previous reports. ${ }^{13}$ and probably because of a higher incidence of Folic Acid deficiency in our study group. Renal System anomalies were the second most common in our study. Most out of these, i.e. 11 had Hydronephrosis. Although, Cardiac anomalies are the commonest anomalies worldwide, they were third most common in our study. This could be attributed to late registration of patients for antenatal checkup and subsequent loss of critical midtrimester period for cardiac anomaly detection.

The EUROCAT. ${ }^{14}$ study, a large international registry in Europe that has been in existence for over 30 years has provided much of the available information regarding risks associated with foetal anomalies. ${ }^{15}$ The differences in occurrence, prevalence or ultrasound detection of various systemic anomalies when compared to the EUROCAT study could be because of differences in ethnicity, geographic location, maternal nutritional status and patient awareness regarding antenatal care.

In our study, we found that pregnancies complicated by congenital anomaly in the foetus are at an increased risk of stillbirth. Our finding that there is an association between foetal abnormality and stillbirth is consistent with prior studies.13,16,17 Underreporting in our study would have resulted from enrollment of some pregnant women in the third trimester, a lack of postmortem examination of stillborn infants and lack of genetic studies for genetic and syndromic defects, all of these may have resulted in an underestimation of the overall prevalence of congenital anomalies. However, our study provides a fair representation of data on congenital anomalies in a typical central Indian population.

\section{CONCLUSION}

Obstetric care providers should be very conscious about counselling the patients diagnosed to be carrying anomalous child on Ultrasound, regarding subsequent prognosis including high risk of stillbirth. As developing countries continue to see a decline in childhood infectious diseases, congenital anomalies will take on a greater significance as a cause of morbidity and mortality. Early diagnosis will prevent mothers from psychological trauma of bearing and rearing an anomalous child.

\begin{tabular}{|c|c|c|}
\hline $\begin{array}{c}\text { Age Group } \\
\text { (In years) }\end{array}$ & $\begin{array}{c}\text { No. of } \\
\text { Women }\end{array}$ & \% \\
\hline$<20$ & 2 & 2.9 \\
\hline $20-24$ & 34 & 50.7 \\
\hline $25-29$ & 22 & 32.8 \\
\hline $30-34$ & 7 & 10.4 \\
\hline$>35$ & 2 & 2.9 \\
\hline \multicolumn{2}{|c|}{ Table 1: Age Wise Distribution of Study Group } \\
\hline
\end{tabular}

\begin{tabular}{|c|c|c|}
\hline $\begin{array}{c}\text { Gestational Age } \\
\text { in Weeks }\end{array}$ & $\begin{array}{c}\text { No. of } \\
\text { Women }\end{array}$ & $\%$ \\
\hline$<20$ & 11 & 16 \\
\hline $21-25$ & 10 & 15 \\
\hline $26-30$ & 17 & 25 \\
\hline $31-35$ & 22 & 33 \\
\hline$>35$ & 7 & 11 \\
\hline \multicolumn{2}{|c|}{ Table 2: Distribution of Patients According to } \\
Gestational Age at the Time of Diagnosis \\
\hline
\end{tabular}

\begin{tabular}{|c|c|c|}
\hline Type of Anomaly & $\begin{array}{c}\text { No. of } \\
\text { Women }\end{array}$ & \% \\
\hline Central Nervous System & 23 & 34.3 \\
\hline Renal System & 16 & 23.8 \\
\hline Cardiovascular System & 10 & 14.9 \\
\hline Body Wall Defects & 9 & 13.4 \\
\hline Respiratory System & 5 & 7.4 \\
\hline Gastrointestinal System & 4 & 5.9 \\
\hline \multicolumn{2}{|c|}{ Table 3: System Wise Distribution of Cases } \\
\hline
\end{tabular}

\begin{tabular}{|c|c|c|c|c|c|}
\hline & \multicolumn{2}{|c|}{$\begin{array}{c}\text { Congenital } \\
\text { Anomaly } \\
\text { Present } \\
\end{array}$} & \multicolumn{2}{|c|}{$\begin{array}{c}\text { Congenital } \\
\text { Anomaly Absent }\end{array}$} & \multirow[t]{2}{*}{ Or } \\
\hline $\begin{array}{l}\text { Number } \\
\text { of Still- } \\
\text { births }\end{array}$ & 6 & \multirow{2}{*}{$\begin{array}{l}\text { Stillbirth } \\
\text { rate } \\
89.5 / 1000 \\
\text { Births }\end{array}$} & 57 & \multirow{2}{*}{$\begin{array}{l}\text { Stillbirth } \\
\text { rate } \\
23 / 1000 \\
\text { Births }\end{array}$} & \\
\hline $\begin{array}{l}\text { Number } \\
\text { of } \\
\text { Pregnan } \\
\text { cies }\end{array}$ & 67 & & 2468 & & 4.16 \\
\hline \multicolumn{6}{|c|}{$\begin{array}{l}\text { Table 4: Association between } \\
\text { Congenital Anomalies and Stillbirths }\end{array}$} \\
\hline
\end{tabular}

\section{REFERENCES}

1. Carmona RH. The global challenges of birth defects and disabilities. Lancet 2005;366(9492):1142-1144.

2. Patel ZM, Adhia RA. Birth defects surveillance study. Indian J Paediatr 2005;72(6):489-91.

3. World health organization. Section on congenital anomalies. Available from: http://www.who.int/mediacentre/factsheets/fs370/en/ 2012.

4. Bhat BV, Ravikumara M. Perinatal mortality in India-Need for introspection. Indian J Matern Child Health 1996;7:313.

5. Agarwal SS, Singh U, Singh PS, et al. Prevalence and spectrum of congenital malformations in a prospective study at a teaching hospital. Indian J Med Res 1991;94:413-9.

6. Stillbirth collaborative research network. Causes of death among stillbirths. JAMA 2011; 306(22):2459-2468.

7. ACOG practice bulletin No. 102, Management of stillbirth. Obstet Gynecol 2009;113(3):748-761.

8. ACOG Practice bulletin no. 134: Fetal growth restriction. Obstet Gynecol 2013;121(5):1122-1133. 
9. Mohanty C, Mishra OP, Das BK, et al. Congenital malformations in newborns: a study of 10,874 consecutive births. J AnatSoc India 1989;38:101-11.

10. Birch MR, Grayson N, Sullivan EA. Recommendations for development of a new Australian birth anomalies system: a review of the congenital malformations and birth defects data collection. AIHW Cat. No. PER 23.Birth anomalies series No. 1. Sydney: AIHW National Perinatal Statistics Unit 2004.

11. Khatemi F, Mamoori GA. Survey of congenital major malformations in 10/000 newborns. Iran J Pediatr 2005;15(4):315-20.

12. Dutta V, Chaturvedi P. Congenital malformations in rural Maharashtra. Indian Pediatr 2000;37:998-1001.
13. Dolk H, Loane M, Garne E. The prevalence of congenital anomalies in Europe. Adv Exp Med Biol 2010;686:349-364.

14. EUROCAT. Prenatal detection rates. Available at: http://www.eurocatnetwork, eu/prenatal screening and diagnosis/prenatal detection (pd)rates 2012.

15. Boyd PA, Haeusler M, Barisic I, et al. Paper 1: The EUROCAT network-organization and processes. Birth Defects Res A Clin Mol Teratol 2011;91(Suppl 1):S2-S15.

16. Getahun D, Ananth CV, Kinzler WL. Risk factors for antepartum and intrapartum stillbirth: a population-based study. Am J Obstet Gynecol 2007;196(6):499-507.

17. Facchinetti F, Alberico S, Benedetto $\mathrm{C}$, et al. A multicenter, case-control study on risk factors for antepartum stillbirth. J Matern Fetal Neonatal Med 2011;24(3):407-410. 